\title{
Anticipation of Monetary Reward in Amygdala, Insula, Caudate are Predictors of Pleasure Sensitivity to d-Amphetamine Administration
}

\author{
Scott A. Langenecker ${ }^{a, b}$, Leah R. Kling ${ }^{b}$, Natania A. Crane ${ }^{b}$, Stephanie M. Gorka ${ }^{b}$, Robin \\ Nusslock $^{c}$, Katherine S. F. Damme ${ }^{c}$, Jessica Weafer ${ }^{d}$, Harriet de Wit ${ }^{d,}{ }^{*}$, K. Luan Phan ${ }^{b, e, f,{ }^{*}}$ \\ aDepartment of Psychiatry, University of Utah, 501 Chipeta Way, Salt Lake City, UT 84108, USA \\ bDepartment of Psychiatry, University of Illinois at Chicago, 1601 W Taylor St, Chicago, IL 60612, \\ USA
}

'Department of Psychology, Northwestern University, Swift Hall 102, 2029 Sheridan Road, Evanston, IL 60208

dDepartment of Psychiatry and Behavioral Neuroscience, University of Chicago, Billings Hospital, 5841 S. Maryland Avenue, Chicago, IL 60637, USA

eMental Health Service Line, Jesse Brown VA Medical Center, 820 S Damen Ave, Chicago, IL 60612, USA

fDepartment of Psychiatry and Behavioral Health, The Ohio State University, OSU Harding Hospital, 1670 Upham Drive, Suite 130, Columbus, OH 43210

\begin{abstract}
Background-Drug addiction and dependence continue as an unresolved source of morbidity and mortality. Two approaches to identifying risk for abuse and addiction are psychopharmacological challenge studies and neuroimaging experiments. The present study
\end{abstract}

Please address correspondence to Scott A. Langenecker, Ph.D. 501 Chipeta Way, Salt Lake City, UT 84108, USA, s.langenecker@hsc.utah.edu.

Contributors

SAL: Performed the background search, computed the analyses, wrote and edited the manuscript, assisted in designing the study.

LRK. Assisted in data collection, performed background searches, analyzed data, assisted in writing and editing.

NAC. Assisted in data collection and analysis, assisted in defining ROIs, assisted in writing and editing.

SMG. Assisted in data collection and analysis, assisted in defining ROIs, assisted in writing and editing.

RN. Assisted in task selection and design. assisted in writing and editing.

KSFD. Assisted in task selection and design, data analysis. assisted in writing and editing.

JW. Assisted in data collection. assisted in writing and editing.

HdW. Designed study and experiments. Assisted in task selection and design, data analysis. assisted in writing and editing.

KLP. Designed study and experiments. Assisted in task selection and design, data analysis. assisted in writing and editing.

*These authors contributed equally to this work

Publisher's Disclaimer: This is a PDF file of an unedited manuscript that has been accepted for publication. As a service to our customers we are providing this early version of the manuscript. The manuscript will undergo copyediting, typesetting, and review of the resulting proof before it is published in its final form. Please note that during the production process errors may be discovered which could affect the content, and all legal disclaimers that apply to the journal pertain.

Conflict of Interest

H.d.W. received consulting fees from Jazz Pharmaceuticals, research support in the form of a GRAND award from Pfizer, support for a research study from Insys Therapeutics, and a donation of a research drug from Indivior. None of these were related to the research reported here. All the other authors declare no competing interests. 
combined these two approaches by examining associations between self-reported euphoria or liking after a dose of d-amphetamine and neural-based responses to anticipation of a monetary reward.

Methods-Healthy young adults ( $=73)$ aged 19 and 26, without any history of alcohol/ substance dependence completed four laboratory sessions in which they received oral damphetamine $(20 \mathrm{mg})$ or placebo, and completed drug effect questionnaires. On a separate session they underwent a functional magnetic resonance imaging scan while they completed a monetary incentive delay task. During the task, we recorded neural signal related to anticipation of winning $\$ 5$ or $\$ 1$ compared to winning no money (WinMoney-WinZero), in reward related regions.

Results-Liking of amphetamine during the drug sessions was related to differences in activation during the WinMoney-WinZero conditions - in the amygdala (positive), insula (negative) and caudate (negative). In posthoc analyses, liking of amphetamine was also positively correlated with activation of the amygdala during anticipation of large rewards and negatively related to activation of the left insula to both small and large anticipated rewards.

Conclusions-These findings suggest that individual differences in key regions of the reward network are related to rewarding subjective effects of a stimulant drug. To further clarify these relationships, future pharmacofMRI studies could probe the influence of amphetamine at the neural level during reward anticipation.

\section{Keywords}

d-amphetamine; reward anticipation; substance abuse; fMRI

\section{Introduction}

There is substantial morbidity and burden associated with substance use disorders, and little is known about the neurobiological risk factors that predict repeated or excessive use of drugs. Identifying predictors of risk for substance abuse would facilitate both prevention and treatment efforts. One source of risk for continued use is the initial subjective responses experienced from a drug. That is, individuals who experience pleasurable effects from drugs during their early experiences may be more likely to reuse the drugs and progress to problem use (de Wit and Phillips, 2012). Individuals differ in their acute responses to drugs for many reasons, including expectancies, biological affinities, and prior drug use (Ashok et al., 2017; Bjork et al., 2008; Casey et al., 2014; Cope et al., 2019; Kassel, et al., 2005; Koob, 1999; Nelson et al., 2015; Peters et al., 2017; Salamone and Correa, 2012; Steele et al., 2018). Another possible source of risk for drug use, and one that may be related to variability in rewarding effects of amphetamine, is individual differences in functioning of the brain's 'reward' and related systems.

Stimulant drugs are known to engage circuitry in the mesolimbic dopamine system, which is integrally involved in neural processing of reward (Volkow et al., 2009). Stimulant drugs like amphetamine and methylphenidate increase synaptic levels of dopamine in the ventral striatum (VS), putamen, and caudate, and these increases are correlated with positive subjective responses to the drugs (Oswald et al., 2005; Smith et al., 2016). Positive subjective responses to stimulants are also related to dopamine cell activity, levels of D2

Drug Alcohol Depend. Author manuscript; available in PMC 2021 January 01. 
receptors, and level of D2/D3 receptor binding (Abi-Dargham et al., 2003; Calipari et al., 2015; Drevets et al., 2001; Leyton et al., 2002; Martinez et al., 2003; Volkow et al., 2002). We recently reported that, in healthy volunteers, methamphetamine acutely increases resting state functional connectivity between the striatum and medial and lateral frontal regions, and that less drug-induced connectivity between the putamen and left inferior frontal gyrus is associated with greater drug-induced euphoria (Weafer, Van Hedger et al. 2019). Chronic use of stimulants is associated with lower dopamine release, transporter availability and D2/D3 availability (Ashok et al., 2017; Letchworth et al., 2001). Individuals who have recently developed stimulant use disorders, but not those with chronic stimulant dependence, show exaggerated neural processing of a sensory reward, pleasant soft touch to the skin (Stewart et al., 2015). In a metaanalysis of fMRI studies with studies in stimulant-dependent individuals Ersche et al (2013) concluded that there is a decline in gray matter in the prefrontal cortex regions after stimulant use, and this was associated with impaired selfregulation and self-awareness. These findings suggest that stimulant drugs alter brain function in reward-related processes, but most studies are limited by the fact that the differences may have pre-dated problem drug use.

There is some evidence that pre-existing differences in brain function predict response to stimulants. One study reported that non-addicted individuals at high risk for addiction because of a multigenerational family history of drug abuse exhibited a lower response to amphetamine in the ventral striatum (VS), putamen, and caudate, compared to individuals without this family history (Casey et al., 2014). A longitudinal study (Becker et al, 2015) examining regional brain volumes in individuals who reported occasional stimulant use at baseline and 12 and 24 months later observed that individuals who subsequently increased stimulant use displayed smaller medial prefrontal cortex, basolateral amygdala and dorsal striatum volumes at baseline. Taken together, these findings suggest that individual differences in brain reward function may predict emotional responses (e.g., liking, euphoria) to challenge dose of a stimulant drug in healthy non-drug using volunteers.

One way to study the function of the dopamine reward system is using monetary reward tasks that activate the frontal, limbic and subcortical regions associated with reward, motivation, and salience. Key regions associated with these functions include VS, which includes the nucleus accumbens (NAcc), caudate, and putamen, plus insula and amygdala regions that are implicated in identifying and tagging salient experiences associated with pleasure and pain. fMRI and EEG studies show that these regions are activated during both anticipation of reward, receipt of reward, and addiction (Breiter, 2001; Carl et al., 2016; Crane et al., 2018; Droutman et al., 2015; Hasler et al., 2013; Knutson and Cooper, 2005; Motzkin et al., 2014; Satterthwaite et al., 2015; Villafuerte et al.; Weafer et al., 2017).

The task most commonly used to activate this reward circuit is the monetary incentive delay task (MID; (Buckholtz et al., 2010; Knutson et al., 2001; Knutson et al., 2008; Knutson and Cooper, 2005; Samanez-Larkin et al., 2007; Samanez-Larkin et al., 2008; Scott et al., 2008)), and variants of the task (Simon et al., 2014; Wilson et al., 2018; Yi et al., 2019). In this task, visual cues predict opportunities to either win or lose monetary rewards. In the version of the task used here, trials are auto-titrated versions to maximize the reward system response. That is, the difficulty in response times is titrated across trials to optimize 
performance to a relatively challenging range of $60-80 \%$ success rate. This task is thought to uniformly engage relevant regions, in a circuit-based manner.

Anticipation of reward typically results in activation of NAcc, caudate, anterior insula, medial prefrontal cortex, and lateral prefrontal cortex (Breiter et al., 2001; Knutson, 2001; O'Doherty et al., 2001; Pochon et al., 2002), although this has not been observed all studies (Knutson and Cooper, 2005; Muller et al., 2010). Notably, the circuit appears to be more responsive to the anticipation of reward than to receipt of reward, in particular the ventral basal ganglia (Salamone and Correa, 2012). Interestingly, recent studies of early adolescents have demonstrated prospectively that lower activation of NAcc to anticipation of reward in the MID predicted initiation of substance use by age 16 in a high risk sample of youth (Büchel et al., 2017; Cope et al., 2019). Therefore, during anticipation of reward, the MID task seems to reliably activate reward-associated brain regions and this activation may be a sensitive biomarker for substance use risk.

In summary, this study was designed to examine relationships between two risk factors for substance abuse: subjective response to amphetamine and neural response to rewards. The goal of the present study was to determine whether amphetamine-associated liking/euphoria was correlated with activation of the brain reward system during anticipation of monetary rewards in healthy young adults. It expands on an earlier report using a subset of this sample ( $N=61$; Crane et al., 2018), in which we examined a Win-Loss contrast in another reward task, the Gambling Reward task (Forbes et al., 2006). In that study, participants who reported greater liking/euphoria after amphetamine exhibited greater neural activation during anticipation of reward (in wins vs losses) in mesolimbic reward regions, including the bilateral caudate and putamen. The present study extended these observations to a larger sample and a different reward task. Unlike the Gambling Reward task which required no response and only assessed responses to wins, the MID task used in the present study required subjects to perform a response to obtain rewards, and it provided cues signaling win vs loss trials to model the preparatory anticipation phase. The task also included two reward values (i.e., wins of $\$ 1.50$ or $\$ 5$ ). This more complex task provided opportunities to detect more nuanced relationships between amphetamine liking and neural responses to reward.

Therefore, the present study examined whether neural response during anticipation of reward was associated with liking/euphoria of a single dose of d-amphetamine in healthy young adults. Subjective responses to d-amphetamine were determined in a behavioral laboratory setting, in which participants received d-amphetamine $(20 \mathrm{mg})$ and placebo under double blind conditions. They completed questionnaires assessing drug liking and euphoria. Brain activation during anticipation and receipt of reward was determined on a separate fMRI scanning session in which participants completed a modified monetary incentive delay (MID) task. without drug administration. We predicted that euphoric/liking response to amphetamine would be positively correlated with activation of reward-related brain regions when subjects anticipated the opportunity to win money. 


\section{Materials and methods}

\subsection{Participants and procedures}

Healthy men and women ( $\mathrm{N}=82$, final sample $\mathrm{N}=73$ ) aged 19-26 were recruited by posters and ads. They underwent medical and psychiatric screening, including an electrocardiogram, physical exam and psychiatric interview with a clinical psychologist. Drug use histories were obtained. Participants were excluded if they had current DSM-V diagnosis (2013) any lifetime history of Alcohol or Substance Use Disorder, or contraindication for fMRI. Participants were not required to be amphetamine naïve. Participants were excluded if they smoked more than 5 tobacco cigarettes per day or if they were daily cannabis users. Exclusion criteria were less than high school education, lack of fluency in English, any current medication or serious medical disorders or night shift work. Women were excluded if they were pregnant, lactating, or planning to become pregnant in the next 3 months. Women who were not on hormonal contraception completed the drug administration sessions during the follicular phase of the menstrual cycle (White et al., 2002). Subjects provided informed consent and the study was conducted in accordance with the declaration of Helsinki and approved by IRBs at the University of Chicago and the University of Illinois at Chicago.

\subsection{Design and drug administration sessions}

The study used a within-subject, double-blind design consisting of five sessions. The first four sessions were 4-hour drug administration sessions in which subjects received capsules containing either placebo or d-amphetamine $(20 \mathrm{mg})$ on two occasions each, under double blind conditions. At least 1 week later participants attended an fMRI session in which they completed the MID (Crane et al., 2018).

The four drug administration sessions were conducted in comfortable rooms in the behavioral laboratory at the University of Chicago from 9 am to $1 \mathrm{pm}$, at least 48 hours apart. Upon arrival subjects provided breath and urine samples to exclude individuals with recent drug use or pregnancy (women). They completed pre-drug questionnaires and cardiovascular measures were obtained (see below). Then they ingested a capsule containing d-amphetamine $(20 \mathrm{mg}$ ) or placebo. d-Amphetamine sulfate (5 mg tablets, TEVA Pharmaceuticals) was placed in size 00 opaque capsules with dextrose filler, and placebo contained dextrose only. Subjective response details on the experiment are reported elsewhere (Weafer et al., 2017). Drug and placebo were administered in alternating order, and half the subjects received each of the two orders (i.e., drug first or placebo first). There was no eating during sessions. To minimize expectancies participants were told they could receive a stimulant, sedative, or placebo. At 30-min intervals for the remainder of the session subjects again completed the questionnaires reporting on the mood and drug effects, and cardiovascular measures were obtained.

To assess positive subjective responses to amphetamine we created a composite score based on subjects' ratings on the MBG ("Euphoria") scale of the Addiction Research Center Inventory (Martin et al., 1971) and ratings of Drug Liking on the Drug Effects questionnaire (Morean et al., 2013). For each subject, we calculated the peak change from baseline score 
from before capsule to the highest value (ARCI) or peak score (highest value, on DEQ) during the 4-hour session, for both amphetamine and placebo. We then subtracted peak change from baseline scores following placebo from those following amphetamine to create peak change difference (drug minus placebo) scores for each measure (Crane et al. 2018). We then standardized these difference scores, and averaged the two. This constituted the aggregate of euphoria and liking, hereafter the Amphetamine Euphoria Response (AER). The AER was the primary dependent variable to be examined in relation to brain activation during anticipation of reward. Further details of procedure and results of the drug sessions are reported elsewhere (Weafer et al., 2017).

\subsection{Scanning session and MID task}

On the fifth session, participants completed a functional MRI at the University of Illinois at Chicago (UIC). Prior to the scan, they provided urine and breath samples to detect recent drug use or pregnancy. During the scan, subjects completed the modified MID (Figure 1) task. In this version of the MID the speed of the response window was automatically adjusted (Samanez-Larkin et al., 2007) to ensure that performance on the task was similar across individuals. That is, every individual has the same probability of gaining $(\sim 66 \%)$ or avoiding losing money ( $66 \%)$, providing an optimal window of difficult to engage reward circuitry (Knutson et al., 2001; Knutson et al., 2008).

The MID task was completed in two runs of 9.6 minutes (Samanez-Larkin et al., 2008). Each run consisted of 120 trials. On each trial, subjects were provided with a cue indicating whether the trial is a win or loss trial, and the amount of money they might win $(\$ 0, \$ 1.50$, or $\$ 5$ types of trials, Figure 1). Subjects completed 20 counterbalanced trials of each type. The WinZero trials were contrasted with Big WinMoney trials (i.e. \$5) and Small WinMoney trials (i.e. \$1.50), which for this analysis were equally weighted (hereafter WinMoney) in the hemodynamic modeling. In a secondary analysis, we examined WinMoney only trials in relation to the hemodynamic baseline (e.g., onset of cue). There is debate on whether the WinZero or baseline signal is the most appropriate condition for comparisons (active contrast or passive deconvolution model), so we include both. The Supplement ${ }^{1}$ includes LoseMoney trials (Big LossMoney of $\$ 5$ and Small LossMoney of \$1.50) in relation to LoseZero trials (Samanez-Larkin et al., 2007) as these responses are not hypothesized to be related to amphetamine liking. The Supplement ${ }^{1}$ also includes an alternative contrast (WinMoney minus LoseMoney for comparison with our prior report (Crane et al., 2018). Straightforward contrasts of these main effects were thresholded at $\mathrm{p}<$. 0001 and $\mathrm{k}>150$.

\subsection{MRI data acquisition and preprocessing}

A GE 3T Discovery Scanner was used at the UIC Center for Magnetic Resonance Research. $\mathrm{T} 2$ star images were collected with a $3 \mathrm{~mm}$ slice thickness to acquire 44 axial slices in an interleaved order. A 0mm gap was used, and TR of 2000 . There was an $82^{\circ}$ flip, with $25 \mathrm{~ms}$ $\mathrm{TE}$, and $20 \mathrm{~cm}$ FOV with a $64 \times 64$ matrix. A standardized sequence was used for data preprocessing, including conversion from DICOM to NII images, despiking with AFNI,

\footnotetext{
${ }^{1}$ Supplementary material can be found by accessing the online version of this paper.
} 
slice timing and realignment (with resampled voxel sizes of $2 * 2 * 2 \mathrm{~mm}$ ) in FSL, and normalization and smoothing (5mm FWHM) within SPM8. The combined packages were used based upon prior data screening of the steps within each respective package, settling on optimal effectiveness at each step. Participants were pre-screened for excessive movement, and those individuals with greater than $1.5 \mathrm{~mm}$ displacement in any image to image acquisition, or exceeding $3 \mathrm{~mm}$ over the entire scan, or with distorted data were excluded $(n=9)$. Twenty-six individuals had some degree of movement in one scan, such that only one run was used to model results instead of two. The predictive results for WinMoney-WinZero were identical if these 26 (with modeled data from one run) were included or not, so we report results with the full model of 73 individuals.

\subsection{Region of Interest Selection}

We conducted a planned ROI analysis of five bilateral regions in key reward-related regions, including the NAcc, putamen, caudate, amygdala, and insula (Haber-https:// www.ncbi.nlm.nih.gov/books/NBK92777/). Note that these regions are illustrated in Neurosynth for reward anticipation, but this does not uniformly designate these regions as reward specific. The five bilateral anatomical seeds were defined via the AAL atlas and created using MARINA (http://www.bion.de/Marina.htm; (Walter et al., 2003, see Supplemental Figure $1^{2}$ ). The parameter estimates/ $\beta$-weights were extracted for each participant from seed ROIs representing BOLD signal response (parameter estimates, arbitrary units [a.u.]) averaged across all voxels within the anatomical masks for the anticipation contrasts of interest (e.g., WinMoney-WinZero).

\subsection{Data Analysis}

The ten ROI values (activation for WinMoney-WinZero, or the WinMoney-baseline) were employed in two backward regression models in relation to AER. Order of amphetamine administration, age, and sex were entered into the backward regression at level 1 as covariates of interest, and were retained if significant. An alpha of $\mathrm{p}<.05$ was used for each of the two regression models. Posthoc analyses subdivided win and loss conditions into Big and Small amounts as noted in the task description above (section 2.4).

\section{Results}

\subsection{MID Anticipation Activation for WinMoney minus WinZero}

The regions engaged in the difference between anticipating WinMoney and anticipating no money (WinZero, WinMoney-WinZero) are illustrated in Figure 2 (positive activation is green, negative activation is red; the loss analyses are included for comparison only, green and fuscia, respectively, Threshold displayed at $\mathrm{p}<.0001$ and $\mathrm{k}>150$ ). In particular, as fMRI hemodynamic response function (HRF) signal is a relative BOLD change, there is an increase in NAcc response to anticipation (see description below). We observed an increase in activation in the WinMoney-WinZero conditions in all ROIs except the amygdala (Figure 2B).

\footnotetext{
${ }^{2}$ Supplementary material can be found by accessing the online version of this paper.
} 
AER was significantly related to activation in three ROIs (amygdala, insula, and caudate, $\mathrm{F}$ $(3,67)=4.38, \mathrm{p}=.007, \mathrm{R}^{2}=.12$, individual beta weights are reported in Table 2). Drug order, age and sex were not significant predictors. Unstandardized values from the regression model were saved from the model for these three predictors. The relation of these unstandardized values to AER, are illustrated in Figure 3, Panel A.

In posthoc analyses, we separately examined predictors of brain activation for Big (\$5) and Small (\$1) anticipation prompts (Big WinMoney, Small WinMoney). We evaluated activation during anticipation of Big WinMoney relative to WinZero, in each of the three ROI's. We evaluated the same basic contrast for Small WinMoney in relation to WinZero. As illustrated in Figure 3 (Panels B and D), both right and left amygdala demonstrated stronger relationships with the combined three neural predictors of AER from Figure 3, for Big WinMoney - WinZero. This relationship was neglible for the Small WinMoney WinZero contrast. In comparison, greater left insula activation for both Big WinMoney WinZero and Small WinMoney-WinZero contrasts were each equally associated with less AER (Figure 3, Panel C).

\subsection{MID Anticipation Activation for WinMoney Alone}

As an alternative model, we used the HRF response during WinMoney only, using as a comparison the implicit baseline modeled by SPM (i.e., without subtracting the activation during the WinZero WinZero), to predict AER (Samanez-Larkin et al., 2007). The combined model with all ten ROIs was significant in prediction of AER $(\mathrm{F}(8,62)=2.35, \mathrm{p}=.03$, adjusted $\mathrm{R}^{2}=.16$ ). None of the level 1 demographic and procedural covariates were significant predictors. A simpler model (with only three reward-associated ROIs) was also significant predictor of AER and identical in adjusted $\mathrm{R}^{2}$ (in Table $2, \mathrm{~F}(2,67)=5.48, \mathrm{p}=$. $002, R^{2}=.16$ ). Scatter plot for this regression model (unstandardized value) is depicted in Figure 4.

\subsection{Posthoc Relationships of MID ROI Activation with Measures of Daily Substance Use.}

The participants in this study used relatively low levels of nonmedical drugs, and had no history of substance use. Nonetheless, to examine individual differences in low levels of use in relation to brain activation during reward anticipation we conducted an exploratory analysis of relationships between prior drug use (caffeine, nicotine use by day, alcohol use by week, and cannabis use by month) and activation during the MID. Each substance was evaluated separately in a multiple regression model. For WinMoney-WinZero, activation in right and left NAcc, and right insula was inversely related to daily caffeine use (right NAcc shown in Supp Figure 2). This relationship remained significant even after excluding the 7 participants who consumed 3 or more cups of caffeine per day (Sections 3.1. and 3.2. above). There were no relationships with level of nicotine use, level of alcohol use, and level of cannabis use for activation in these ROIs, For WinMoney alone, there were no significant relationships between activation and any low-level measures of substance use. 


\section{Discussion}

The results of the present study suggest that key regions often considered within the reward network are indeed engaged with a reward task, and that this activation is related to amphetamine liking/euphoria. Of course, these relationships do not suggest any degree of causation, and they only describe an early phase of addiction risk potential. The relationship was observed in individuals with little or no prior experience with stimulant drugs, suggesting that there are shared mechanisms involved in neural processing of monetary rewards and initial pleasurable effects of a stimulant drug. In the present study we demonstrated relationships between two biomarkers for substance abuse risk: higher responsiveness to the anticipation of monetary reward (compared to no reward) in the amygdala, insula, caudate and NAcc during a non-intoxicated state using the MID task and liking/euphoria of a moderate dose of amphetamine, extending and replicating certain aspects of our prior study (as reported below, Crane et al., 2018). Here specifically, greater activity in the left amygdala during anticipation of larger wins and to a lesser extent in the right amygdala, were associated with AER, whereas an inverse relationship was observed in left insula, such that greater left insula activation was associated with less amphetamine liking/euphoria for anticipation of wins of larger and smaller magnitude. In alternative models, activation during anticipation in right caudate (positive) and right NAcc (negative) were associated with AER. The pairing of these two biological markers (AER and fMRI response to reward) aligns with the idea that there could be a biological underpinning to risk for experiencing positive subjective effects from a stimulant, which may predispose an individual for substance use. The observations are consistent with the NIMH RDoC initiative that biomarkers may aggregate across modalities of assay/inquiry. This approach may increased the accuracy of predictions of the transition from initial substance use to abuse or addiction/dependence.

\subsection{The Role of Amygdala in Reward Anticipation and Risk for Substance Abuse}

The amygdala, bilaterally, was a contributor to prediction of AER to d-amphetamine in this sample, particularly for large MoneyWins-ZeroMoney trials. There is a substantial literature indicating that the amygdala is involved not only in salience of threat, but also the detection of stimuli with positive valence. The present finding of a relationship between large wins and AER is consistent with these reports (Duncan et al., 1986; Filbey et al., 2014; Hamaan and Mao, 2002; Hu et al., 2018; Koob, 1999; Lemche et al., 2006; Lopez-Caneda et al., 2014; Munier et al., 2017; Sjoerds et al., 2014; Stuhrmann et al., 2011; Tillman et al., 2017; Yang et al., 2002). The activation of the amygdala could reflect either a preparatory response for the upcoming motor response, or the anticipation of an upcoming reward. Note, however, that the signal varied across individuals, appearing only in individuals who reported liking/ euphoria for amphetamine (e.g., those with low/negative AER also had decreased amygdala activation).

Other research suggests that the amygdala, and the reward-associated regions more broadly, are inversely coupled with regulatory regions, which constitute a network often referred to as the "cognitive control network '(Jenkins et al., 2017; Klumpp et al., 2014; Kujawa et al., 2016; Langenecker et al., 2014; Okita et al., 2016; Phan et al., 2005; Weafer et al., 2019; Wu

Drug Alcohol Depend. Author manuscript; available in PMC 2021 January 01. 
et al., 2016). As such, engagement of amygdala during anticipation of rewards may simultaneously diminish capacity for these regulatory circuits, an essential inverse relationship between control and reward seeking (Crowley et al., 2010; Peters et al., 2017; Steele et al., 2018). This pattern is often observed most obviously in those with impulse associated disorders, more broadly externalizing disorders like substance use disorders (Crowley et al., 2010; Motzkin et al., 2014). Greater reactivity to salience of a stimulus, along with diminished engagement of control circuitry, might place individuals at great risk for using drugs (Elsayed et al., 2018), consistent with the amygdala results reported here.

\subsection{Caudate and NAcc relationships with Amphetamine Euphoria Response}

Unlike the amygdala, activation in the NAcc and caudate were not significantly associated with AER in the Win-Money-WinZero contrast. Notably, however, there was a robust involvement of the NAcc and caudate in anticipating reward (e.g., Figure 2B), perhaps masking individual differences or a ceiling effect obscuring a relationship of brain activation with amphetamine liking. In contrast, the caudate activation for WinMoney Only was a positive predictor of AER, consistent with our recent work with another reward anticipation task in a smaller subset of the sample reported here (Crane et al., 2018). For comparison, we report the sample-comparative results for that task (Gambling Reward) in the Supplement ${ }^{3}$.

The finding that the NAcc was not related to amphetamine liking/euphoria at a dimensional level raises several questions. One possibility is that there was a ceiling effect of NAcc engagement, and that the neural response is so strong in healthy subjects that individual differences are not apparent. It may be that relationships would be evident in at-risk populations, such as those with positive family history of psychiatric conditions (Cope et al., 2019; Heitzeg et al.). As noted previously, NAcc response appears elevated in those at high risk via family history of substance abuse, and dampened in those with current or recent substance abuse (Bjork et al., 2008). Moreover, the neural risk phenotype may be age dependent, such that the NAcc risk signal emerges in early and mid-adolescence and is masked by early adulthood (Ashok et al., 2017; Burkhouse et al., 2019; Cope et al., 2019; Hardee et al., 2014; Hasler et al., 2013; Kassel et al., 2005; McMurray et al., 2015; Munier et al., 2017; Nelson et al., 2015; Satterthwaite et al., 2013; Weinstein and Mermelstein, 2013). Moreover, the lack of association between NAcc activation during monetary reward anticipation and AER does not diminish the relative value of either in predicting risk. Risk moderated by amphetamine liking and that of reward responsiveness may engage different aspects of the mesolimbic reward network. These may sum to greater cumulative risk sensitivity and accuracy.

\subsection{Left Insula and Inverse Relationship with Amphetamine Euphoria Response}

Like the amygdala, the anterior insula has a large role within reward-associated regions, and also in physical and somatic manifestations of drug and reward responses (Bjork et al., 2008; Deen et al., 2011; Elton et al., 2014; Uddin et al., 2017). The fact that we observed an inverse relationship between brain activation during reward anticipation and AER, evident in both WinMoney-WinZero and WinMoney only models, suggests that insula may play a role

\footnotetext{
${ }^{3}$ Supplementary material can be found by accessing the online version of this paper.
} 
in diminishing the pleasurable effect of amphetamine. Engagement of the insula may be linked to both salience of potential adverse outcomes (interoceptive signaling and/or sensitivity to side effects) or may lead to a call for emotional or physiological regulation (diminishing affective and physiological responses) (Deen et al., 2011; Droutman et al., 2015; Langenecker et al., 2018; Lawrence et al., 2009; Nagai et al., 2007; Yeo et al., 2011). As such, it is possible that the role of the insula in addiction is a negative one (greater function and connectivity is a suppressor for addiction), at both the functional and structural level (Droutman et al., 2015). Our ROI included both dorsal anterior and agranular components of the insula, so it could relate to either function, and future research can disentangle these nuances (Chang et al., 2013).

\subsection{Limitations and Implications}

This study had several limitations. First, the design and conclusions were based on correlations between events and responses that occurred across several days. Thus, variability across sessions related to recent sleep, drug use, emotional events or time of day, could have influenced the outcomes. Another limitation, which was also paradoxically a strength, was the relative homogeneity of the sample. The participants were healthy, without extensive drug use histories, without significant psychiatric symptoms, highly educated and within a narrow weight range. This homogeneity helped to reduce uncontrolled variability, but it also may have excluded individuals with the variations in reward function that are most relevant to understanding substance abuse. Other limitations are related to the measures used in the study.

The detection of reward-related neural processes is likely to depend on the task used. The MID task used here differs slightly from other versions of the MID, and from the Gambling Reward Task we used previously (GRT) (Crane et al., 2018). For comparison to the Crane et al findings, we provided the results of analyses using the same predictive modeling in the same subjects, and found that the Win-Loss model from GRT had a relatively higher predictive relationship to amphetamine liking $\left(\mathrm{R}^{2}=.22 \mathrm{vs} \mathrm{R}^{2}=.14\right.$ with MID). Note though, that the GRT includes both wins and losses, and the Win-Fixation contrast did not predict amphetamine liking. The WinMoney minus LoseMoney model was also included for MID in the Supplement ${ }^{4}$, but was not significant. So it may be that the GRT has a closer association with amphetamine liking or that losses are more meaningful for GRT. Adjustments to this task and the GRT might include the ability to include more Big Money trials in the MID, or to better segregate Wins and Losses within the GRT. It is also possible that actually having money at stake based upon a motor response (present in MID but not GRT) confounds measurement in the basal ganglia regions. Future task modifications could include trials with and without a required motor response to better alleviate this concern. Finally, the relative relationship to actual risk for substance use disorder (for MID, GRT, and amphetamine liking) is the true test of the value of these markers in risk prediction. We look forward to continued future studies in this vein.

\footnotetext{
${ }^{4}$ Supplementary material can be found by accessing the online version of this paper.
} 


\subsection{Conclusions}

In summary, the present study shows an association between two biomarkers of potentially increased risk for substance use disorder. Specifically, we found that activation during anticipation of big monetary wins, in both left and right amygdala, was positively associated with degree of AER in a double-blinded, placebo-controlled d-amphetamine administration in healthy young adults. Insula activation during anticipation of All wins was predictive of lower AER. Biological markers that can aid in identification for risk of potential for substance abuse and dependence could lead to new and more timely ways for prevention. This is particularly important in light of evidence that substance use may change the actual biomarkers that could be predictive of risk. Future studies could add a high-risk group for comparison and a longitudinal component to evaluate the relative merit and co-association of these risk biomarkers over time.

\section{Supplementary Material}

Refer to Web version on PubMed Central for supplementary material.

\section{Role of Funding Source}

This publication was funded by the National Institute on Drug Abuse (NIDA) (R01DA002812, PIs: H.d.W. and K.L.P.). S.M.G. was supported by the National Institute on Alcohol Abuse and Alcoholism (NIAAA) (K23AA025111, PI: S.M.G.) and J.W. was supported by NIAAA (K01AA024519, PI: J.W.). Its contents are solely the responsibility of the authors and do not necessarily represent the official views of NIDA, NIAAA, or the National Institutes of Health.

\section{References}

2013 Diagnostic and statistical manual of mental disorders, in: Association, A.P. (Ed.). American Psychiatric Publishing, Arlington, VA.

Abi-Dargham A, Kegeles LS, Martinez D, Innis RB, Laruelle M, 2003 Dopamine mediation of positive reinforcing effects of amphetamine in stimulant naive healthy volunteers: results from a large cohort. Eur Neuropsychopharmacol 13, 459-468. [PubMed: 14636962]

Ashok AH, Mizuno Y, Volkow ND, Howes OD, 2017 Association of Stimulant Use With Dopaminergic Alterations in Users of Cocaine, Amphetamine, or Methamphetamine: A Systematic Review and Meta-analysis. JAMA psychiatry 7), 511-519.

Becker B, Wagner D, Koester P, Tittgemeyer M, Mercer-Chalmers-Bender K, Hurlemann R, Zhang J, Gouzoulis-Mayfrank E, Kendrick KM, Daumann J, 2015 Smaller amygdala and medial prefrontal cortex predict escalating stimulant use. Brain 138, 2074-2086. [PubMed: 25971784]

Bjork JM, Smith AR, Hommer DW, 2008 Striatal sensitivity to reward deliveries and omissions in substance dependent patients. NeuroImage 42, 1609-1621. [PubMed: 18672069]

Breiter H, Aharon I, Kahneman D, Dale AM, Shizgal P, 2001 Functional imaging of neural responses to expectancy and experience of monetary gains and losses. Neuron 30, 619-639. [PubMed: 11395019]

Büchel C, Peters J, Banaschewski T, Bokde ALW, Bromberg U, Conrod PJ, Flor H, Papadopoulos D, Garavan H, Gowland P, Heinz A, Walter H, Ittermann B, Mann K, Martinot J-L, Paillère-Martinot M-L, Nees F, Paus T, Pausova Z, Poustka L, Rietschel M, Robbins TW, Smolka MN, Gallinat J, Schumann G, Knutson B, the, I.c., Arroyo M, Artiges E, Aydin S, Bach C, Barbot A, Barker G, Bruehl R, Cattrell A, Constant P, Crombag H, Czech K, Dalley J, Decideur B, Desrivieres S, Fadai T, Fauth-Buhler M, Feng J, Filippi I, Frouin V, Fuchs B, Gemmeke I, Genauck A, Hanratty E, Heinrichs B, Heym N, Hubner T, Ihlenfeld A, Ing A, Ireland J, Jia T, Jones J, Jurk S, Kaviani M, Klaassen A, Kruschwitz J, Lalanne C, Lanzerath D, Lathrop M, Lawrence C, Lemaitre H, Macare 
C, Mallik C, Mar A, Martinez-Medina L, Mennigen E, de Carvahlo FM, Mignon X, Millenet S, Miranda R, Müller K, Nymberg C, Parchetka C, Pena-Oliver Y, Pentilla J, Poline J-B, Quinlan EB, Rapp M, Ripke S, Ripley T, Robert G, Rogers J, Romanowski A, Ruggeri B, Schmäl C, Schmidt D, Schneider S, Schubert F, Schwartz Y, Sommer W, Spanagel R, Speiser C, Spranger T, Stedman A, Stephens D, Strache N, Ströhle A, Struve M, Subramaniam N, Theobald D, Vetter N, Vulser H, Weiss K, Whelan R, Williams S, Xu B, Yacubian J, Yu T, Ziesch V, 2017 Blunted ventral striatal responses to anticipated rewards foreshadow problematic drug use in novelty-seeking adolescents. Nature communications 8, 14140.

Buckholtz JW, Treadway MT, Cowan RL, Woodward ND, Benning SD, Li R, Ansari MS, Baldwin RM, Schwartzman AN, Shelby ES, Smith CE, Cole D, Kessler RM, Zald DH, 2010 Mesolimbic dopamine reward system hypersensitivity in individuals with psychopathic traits. Nature Neuroscience 13, 419. [PubMed: 20228805]

Burkhouse KL, Stange JP, Jacobs RH, Bhaumik R, Bessette KL, Peters AT, Crane NA, Kreutzer KA, Fitzgerald K, Monk CS, Welsh RC, Phan KL, Langenecker SA, 2019 Developmental changes in resting-state functional networks among individuals with and without internalizing psychopathologies. 36, 141-152.

Calipari ES, Ferris MJ, Siciliano CA, Jones SR, 2015 Differential Influence of Dopamine Transport Rate on the Potencies of Cocaine, Amphetamine, and Methylphenidate. ACS Chemical Neuroscience 6, 155-162. [PubMed: 25474655]

Carl H, Walsh E, Eisenlohr-Moul T, Minkel J, Crowther A, Moore T, Gibbs D, Petty C, Bizzell J, Dichter GS, Smoski MJ, 2016 Sustained anterior cingulate cortex activation during reward processing predicts response to psychotherapy in major depressive disorder. Journal of Affective Disorders 203, 204-212. [PubMed: 27295377]

Casey KF, Benkelfat C, Cherkasova MV, Baker GB, Dagher A, Leyton M, 2014 Reduced Dopamine Response to Amphetamine in Subjects at Ultra-High Risk for Addiction. Biological Psychiatry 76, 23-30. [PubMed: 24138922]

Chang LJ, Yarkoni T, Khaw MW, Sanfey AG, 2013. Decoding the role of the insula in human cognition: functional parcellation and large-scale reverse inference Cerebral cortex (New York, N.Y. : 1991) 23, 739-749.

Cope LM, Martz ME, Hardee JE, Zucker RA, Heitzeg MM, 2019 Reward activation in childhood predicts adolescent substance use initiation in a high-risk sample. Drug and Alcohol Dependence 194, 318-325. [PubMed: 30471583]

Crane NA, Gorka SM, Weafer J, Langenecker SA, de Wit H, Phan KL, 2018 Neural activation to monetary reward is associated with amphetamine reward sensitivity. Neuropsychopharmacology 43, 1738-1744. [PubMed: 29581536]

Crowley TJ, Dalwani MS, Mikulich-Gilbertson SK, Du YP, Lejuez CW, Raymond KM, Banich MT, 2010 Risky Decisions and Their Consequences: Neural Processing by Boys with Antisocial Substance Disorder. PLOS ONE 5, e12835. [PubMed: 20877644]

de Wit H, Phillips TJ, 2012 Do initial responses to drugs predict future use or abuse? Neuroscience \& Biobehavioral Reviews 36, 1565-1576. [PubMed: 22542906]

Deen B, Pitskel NB, Pelphrey KA, 2011 Three systems of insular functional connectivity identified with cluster analysis. Cereb Cortex 21(7), 1498-1506. [PubMed: 21097516]

Drevets WC, Gautier C, Price JC, Kupfer DJ, Kinahan PE, Grace AA, Price JL, Mathis CA, 2001 Amphetamine-induced dopamine release in human ventral striatum correlates with euphoria. Biological psychiatry 49(2), 81-96. [PubMed: 11164755]

Droutman V, Read SJ, Bechara A, 2015 Revisiting the role of the insula in addiction. Trends in Cognitive Sciences 19(7), 414-420. [PubMed: 26066588]

Duncan GE, Breese GR, Criswell H, Stumpf WE, et al., 1986 Effects of antidepressant drugs injected into the amygdala on behavioral responses of rats in the forced swim test. Journal of Pharmacology \& Experimental Therapeutics 238, 758-762. [PubMed: 3016250]

Elsayed NM, Kim MJ, Fields KM, Olvera RL, Hariri AR, Williamson DE, 2018 Trajectories of Alcohol Initiation and Use During Adolescence: The Role of Stress and Amygdala Reactivity. Journal of the American Academy of Child \& Adolescent Psychiatry 57, 550-560. [PubMed: 30071976] 
Elton A, Young J, Smitherman S, Gross RE, Mletzko T, Kilts CD, 2014 Neural network activation during a stop-signal task discriminates cocaine-dependent from non-drug-abusing men. Addict Biol 19, 427-438. [PubMed: 23231419]

Ersche KD, Williams GB, Robbins TW, Bullmore ET, 2013 Meta-analysis of structural brain abnormalities associated with stimulant drug dependence and neuroimaging of addiction vulnerability and resilience. Curr Opin Neurobiol 23, 615-624. [PubMed: 23523373]

Filbey FM, Aslan S, Calhoun VD, Spence JS, Damaraju E, Caprihan A, Segall J, 2014 Long-term effects of marijuana use on the brain. Proc Natl Acad Sci U S A 111, 16913-16918. [PubMed: 25385625]

Forbes EE, May JC, Siegle GJ, Ladouceur CD, Ryan ND, Carter CS, Birmaher B, Axelson DA, Dahl RE, 2006 Reward-related decision-making in pediatric major depressive disorder: an fMRI study. Journal of Child Psychology and Psychiatry 47, 1031-1040. [PubMed: 17073982]

Hamaan S, Mao H, 2002 Positive and negative emotional verbal stimuli elicit activity in the left amygdala. NeuroReport 13, 15-19. [PubMed: 11924878]

Hardee JE, Weiland BJ, Nichols TE, Welsh RC, Soules ME, Steinberg m., Zubieta J-K, Zucker RA, Heitzeg MM, 2014 Development of Impulse Control Circuitry in Children of Alcoholics. Biological Psychiatry 76, 708-716. [PubMed: 24742620]

Hasler BP, Sitnick SL, Shaw DS, Forbes EE, 2013 An altered neural response to reward may contribute to alcohol problems among late adolescents with an evening chronotype. Psychiatry Res 214, 357-364. [PubMed: 24144507]

Heitzeg MM, Nigg JT, Yau WY, Zucker RA, Zubieta JK, Striatal dysfunction marks preexisting risk and medial prefrontal dysfunction is related to problem drinking in children of alcoholics. Biol Psychiatry 68, 287-295. [PubMed: 20416863]

Hu S, Ide JS, Chao HH, Zhornitsky S, Fischer KA, Wang W, Zhang S, Li C.-s.R., 2018 Resting state functional connectivity of the amygdala and problem drinking in non-dependent alcohol drinkers. Drug and Alcohol Dependence 185, 173-180. [PubMed: 29454928]

Jenkins LM, Stange JP, Barba A, DelDonno SR, Kling LR, Briceño EM, Weisenbach SL, Phan KL, Shankman SA, Welsh RC, Langenecker SA, 2017 Integrated cross-network connectivity of amygdala, insula, and subgenual cingulate associated with facial emotion perception in healthy controls and remitted major depressive disorder. Cognitive, Affective, \& Behavioral Neuroscience $17,1242-1254$.

Kassel JD, Weinstein S, Skitch S, Beileux J \& Nerneksteubm R, 2005 The Development of Substance Abuse in Adolescence: Correlates, causes and consequences, in: Hankin BLA, J.R.Z. (Ed.) Developmental psychopathology: A vulnerability-stress perspective. Sage Publications, New York.

Klumpp H, Keutmann MK, Fitzgerald DA, Shankman SA, Phan KL, 2014 Resting state amygdalaprefrontal connectivity predicts symptom change after cognitive behavioral therapy in generalized social anxiety disorder. Biology of mood \& anxiety disorders 4, 1. [PubMed: 24447313]

Knutson B, Bhanji JP, Cooney RE, Atlas LY, Gotlib IH, 2008 Neural responses to monetary incentives in major depression. Biol.Psychiatry 63, 686-692. [PubMed: 17916330]

Knutson B, Cooper JC, 2005 Functional magnetic resonance imaging of reward prediction. Current opinion in neurology 18, 411-417. [PubMed: 16003117]

Knutson B, Fong GW, Adams CM, Varner JL \& Hommer D, 2001 Dissociation of Reward Anticipation and Outcome with Event-Related fMRI. Neuro Report 12, 3683-3687.

Koob GF, 1999 The Role of the Striatopallidal and Extended Amygdala Systems in Drug Addiction. $877,445-460$.

Kujawa A, Wu M, Klumpp H, Pine DS, Swain JE, Fitzgerald KD, Monk CS, Phan KL, 2016 Altered development of amygdala-anterior cingulate cortex connectivity in anxious youth and young adults. Biological Psychiatry: Cognitive Neuroscience and Neuroimaging.

Langenecker SA, Jacobs RH \& Passarotti AM, 2014 Current Neural and Behavioral Dimensional Constructs across Mood Disorders. Current Behavioral Neuroscience Reports 1, 114-153.

Langenecker SA, Jenkins LM, Stange JP, Chang Y-S, DelDonno SR, Bessette KL, Passarotti AM, Bhaumik R, Ajilore O, Jacobs RH, 2018 Cognitive control neuroimaging measures differentiate between those with and without future recurrence of depression. Neuroimage: Clinical 20, 10011009. 
Lawrence NS, Jollant F, O’Daly O, Zelaya F, Phillips ML, 2009 Distinct roles of prefrontal cortical subregions in the Iowa Gambling Task. Cereb Cortex 19, 1134-1143. [PubMed: 18787233]

Lemche E, Giampietro VP, Surguladze SA, Amaro EJ, Andrew CM, Williams SC, Brammer MJ, Lawrence N, Maier MA, Russell TA, Simmons A, Ecker C, Joraschky P, Phillips ML, 2006 Human attachment security is mediated by the amygdala: evidence from combined fMRI and psychophysiological measures. Hum Brain Mapp 27, 623-635. [PubMed: 16284946]

Letchworth SR, Nader MA, Smith HR, Friedman DP, Porrino LJ, 2001 Progression of Changes in Dopamine Transporter Binding Site Density as a Result of Cocaine Self-Administration in Rhesus Monkeys. The Journal of Neuroscience 21, 2799. [PubMed: 11306632]

Leyton M, Boileau I, Benkelfat C, Diksic M, Baker G, Dagher A, 2002 Amphetamine-induced increases in extracellular dopamine, drug wanting, and novelty seeking: a PET/[11C]raclopride study in healthy men. Neuropsychopharmacology : official publication of the American College of Neuropsychopharmacology 27, 1027-1035. [PubMed: 12464459]

Lopez-Caneda E, Rodriguez Holguin S, Cadaveira F, Corral M, Doallo S, 2014 Impact of alcohol use on inhibitory control (and vice versa) during adolescence and young adulthood: a review. Alcohol Alcohol 49, 173-181. [PubMed: 24243684]

Martin WR, Sloan JW, Sapira JD, Jasinski DR, 1971 Physiologic, subjective, and behavioral effects of amphetamine, methamphetamine, ephedrine, phenmetrazine, and methylphenidate in man. Clinical pharmacology and therapeutics 12, 245-258. [PubMed: 5554941]

Martinez D, Slifstein M, Broft A, Mawlawi O, Hwang DR, Huang Y, Cooper T, Kegeles L, Zarahn E, Abi-Dargham A, Haber SN, Laruelle M, 2003 Imaging human mesolimbic dopamine transmission with positron emission tomography. Part II: amphetamine-induced dopamine release in the functional subdivisions of the striatum. J Cereb Blood Flow Metab 23, 285-300. [PubMed: 12621304]

McMurray MS, Amodeo LR, Roitman JD, 2015 Consequences of Adolescent Ethanol Consumption on Risk Preference and Orbitofrontal Cortex Encoding of Reward. Neuropsychopharmacology.

Morean ME, de Wit H, King AC, Sofuoglu M, Rueger SY, O’Malley SS, 2013 The drug effects questionnaire: psychometric support across three drug types. Psychopharmacology 227, 177-192. [PubMed: 23271193]

Motzkin JC, Baskin-Sommers A, Newman JP, Kiehl KA, Koenigs M, 2014 Neural correlates of substance abuse: reduced functional connectivity between areas underlying reward and cognitive control. Hum Brain Mapp 35, 4282-4292. [PubMed: 24510765]

Muller DJ, Likhodi O, Heinz A, 2010 Neural markers of genetic vulnerability to drug addiction. Curr Top Behav Neurosci 3, 277-299. [PubMed: 21161757]

Munier EC, Hardee JE, Cope LM, Zucker RA, Heitzeg MM, Welsh RC, 2017 Sex differences in the development of emotion circuitry in adolescents at risk for substance abuse: a longitudinal fMRI study. Social Cognitive and Affective Neuroscience 12, 965-975. [PubMed: 28338724]

Nagai M, Kishi K, Kato S, 2007 Insular cortex and neuropsychiatric disorders: A review of recent literature. Eur.Psychiatry 22, 387-394. [PubMed: 17416488]

Nelson SE, Van Ryzin MJ, Dishion TJ, 2015 Alcohol, marijuana, and tobacco use trajectories from age 12 to 24 years: demographic correlates and young adult substance use problems. Dev Psychopathol 27, 253-277. [PubMed: 25017089]

O’Doherty J, Kringelbach ML, Rolls ET, Hornak J, Andrews C, 2001 Abstract reward and punishment representations in the human orbitofrontal cortex. Nat.Neurosci 4, 95-102. [PubMed: 11135651]

Okita K, Ghahremani DG, Payer DE, Robertson CL, Dean AC, Mandelkern MA, London ED, 2016 Emotion dysregulation and amygdala dopamine D2-type receptor availability in methamphetamine users. Drug and Alcohol Dependence 161, 163-170. [PubMed: 26880595]

Oswald LM, Wong DF, McCaul M, Zhou Y, Kuwabara H, Choi L, Brasic J, Wand GS, 2005 Relationships among ventral striatal dopamine release, cortisol secretion, and subjective responses to amphetamine. Neuropsychopharmacology : official publication of the American College of Neuropsychopharmacology 30, 821-832. [PubMed: 15702139]

Peters S, Peper JS, Van Duijvenvoorde ACK, Braams BR, Crone EA, 2017 Amygdala-orbitofrontal connectivity predicts alcohol use two years later: a longitudinal neuroimaging study on alcohol use in adolescence. 20, e12448. 
Phan KL, Fitzgerald DA, Nathan PJ, Moore GJ, Uhde TW, Tancer ME, 2005 Neural substrates for voluntary suppression of negative affect: A functional magnetic resonance imaging study. Biological Psychiatry 57, 210-219. [PubMed: 15691521]

Pochon JB, Levy R, Fossati P, Lehericy S, Poline JB, Pillon B, Le Bihan D, DuBois B, 2002 The neural system that bridges reward and cognition in humans: An fMRI study. Proceedings of the National Academy of Sciences of the United States of America 99, 5669-5674. [PubMed: 11960021]

Salamone John D., Correa M, 2012 The Mysterious Motivational Functions of Mesolimbic Dopamine. Neuron 76, 470-485. [PubMed: 23141060]

Samanez-Larkin GR, Gibbs SEB, Khanna K, Nielsen L, Carstensen LL, Knutson B, 2007 Anticipation of monetary gain but not loss in healthy older adults. Nature neuroscience 10, 787-791. [PubMed: 17468751]

Samanez-Larkin GR, Hollon NG, Carstensen LL, Knutson B, 2008 Individual differences in insular sensitivity during loss anticipation predict avoidance learning. Psychol Sci 19, 320-323. [PubMed: 18399882]

Satterthwaite TD, Kable JW, Vandekar L, Katchmar N, Bassett DS, Baldassano CF, Ruparel K, Elliott MA, Sheline YI, Gur RC, Gur RE, Davatzikos C, Leibenluft E, Thase ME, Wolf DH, 2015 Common and Dissociable Dysfunction of the Reward System in Bipolar and Unipolar Depression Reward Dysfunction in Depression. Neuropsychopharmacology.

Satterthwaite TD, Wolf DH, Erus G, Ruparel K, Elliott MA, Gennatas ED, Hopson R, Jackson C, Prabhakaran K, Bilker WB, Calkins ME, Loughead J, Smith A, Roalf DR, Hakonarson H, Verma R, Davatzikos C, Gur RC, Gur RE, 2013 Functional maturation of the executive system during adolescence. J neurosci 33, 16249-16261. [PubMed: 24107956]

Scott DJ, Stohler CS, Egnatuk CM, Wang H, Koeppe RA, Zubieta JK, 2008 Placebo and nocebo effects are defined by opposite opioid and dopaminergic responses. Arch Gen Psychiatry 65, 220 231. [PubMed: 18250260]

Simon JJ, Skunde M, Wu M, Schnell K, Herpertz SC, Bendszus M, Herzog W, Friederich H-C, 2014 Neural dissociation of food- and money-related reward processing using an abstract incentive delay task. Social Cognitive and Affective Neuroscience 10, 1113-1120. [PubMed: 25552570]

Sjoerds Z, van den Brink W, Beekman AT, Penninx BW, Veltman DJ, 2014 Response inhibition in alcohol-dependent patients and patients with depression/anxiety: a functional magnetic resonance imaging study. Psychol Med 44, 1713-1725. [PubMed: 24016382]

Smith CT, Dang LC, Cowan RL, Kessler RM, Zald DH, 2016 Variability in paralimbic dopamine signaling correlates with subjective responses to d-amphetamine. Neuropharmacology 108, 394402. [PubMed: 27174408]

Steele VR, Maurer JM, Arbabshirani MR, Claus ED, Fink BC, Rao V, Calhoun VD, Kiehl KA, 2018 Machine Learning of Functional Magnetic Resonance Imaging Network Connectivity Predicts Substance Abuse Treatment Completion. Biological Psychiatry: Cognitive Neuroscience and Neuroimaging 3, 141-149.

Stewart JL, May AC, Tapert SF, Paulus MP, 2015 Hyperactivation to pleasant interoceptive stimuli characterizes the transition to stimulant addiction. Drug Alcohol Depend 154, 264-270. [PubMed: 26228575]

Stuhrmann A, Suslow T, Dannlowski U, 2011 Facial emotion processing in major depression: a systematic review of neuroimaging findings. Biology of Mood \& Anxiety Disorders 1, 10-10. [PubMed: 22738433]

Tillman R, Stockbridge M, Nacewicz B, Smith J, Shackman A, 2017 124. Functional Architecture of Central Extended Amygdala Networks. Biological Psychiatry 81, S52.

Uddin LQ, Nomi JS, Hébert-Seropian B, Ghaziri J, Boucher O, 2017 Structure and Function of the Human Insula. Journal of clinical neurophysiology : official publication of the American Electroencephalographic Society 34, 300-306. [PubMed: 28644199]

Villafuerte S, Heitzeg MM, Foley S, Wendy Yau WY, Majczenko K, Zubieta JK, Zucker RA, Burmeister M, Impulsiveness and insula activation during reward anticipation are associated with genetic variants in GABRA2 in a family sample enriched for alcoholism. Mol Psychiatry. 
Volkow ND, Fowler JS, Wang GJ, Baler R, Telang F, 2009 Imaging dopamine's role in drug abuse and addiction. Neuropharmacology 56 Suppl, 3-8. [PubMed: 18617195]

Volkow ND, Fowler JS, Wang GJ, Ding YS, Gatley SJ, 2002 Role of dopamine in the therapeutic and reinforcing effects of methylphenidate in humans: results from imaging studies. Eur Neuropsychopharmacol 12, 557-566. [PubMed: 12468018]

Weafer J, Crane NA, Gorka SM, Phan KL, de Wit H, 2019 Neural correlates of inhibition and reward are negatively associated. NeuroImage 196, 188-194. [PubMed: 30974242]

Weafer J, Gorka SM, Hedeker D, Dzemidzic M, Kareken DA, Phan KL, de Wit H, 2017 Associations Between Behavioral and Neural Correlates of Inhibitory Control and Amphetamine Reward Sensitivity. Neuropsychopharmacology 42, 1905-1913. [PubMed: 28303900]

Weafer J, Van Hedger K, Keedy S, Nwaokolo N, de Wit H, 2019 Methamphetamine acutely alters frontostriatal resting state functional connectivity in healthy young adults. Addict Biol. 2019

Weinstein SM, Mermelstein RJ, 2013 Dynamic associations of negative mood and smoking across the development of smoking in adolescence. J Clin Child Adolesc Psychol 42, 629-642. [PubMed: 23682640]

White TL, Justice AJ, de Wit H, 2002 Differential subjective effects of D-amphetamine by gender, hormone levels and menstrual cycle phase. Pharmacology, biochemistry, and behavior 73, 729741.

Wilson RP, Colizzi M, Bossong MG, Allen P, Kempton M, Abe N, Barros-Loscertales AR, Bayer J, Beck A, Bjork J, Boecker R, Bustamante JC, Choi JS, Delmonte S, Dillon D, Figee M, Garavan H, Hagele C, Hermans EJ, Consortium I, Ikeda Y, Kappel V, Kaufmann C, Lamm C, Lammertz SE, Li Y, Murphy A, Nestor L, Pecina M, Pfabigan D, Pizzagalli D, Rademacher L, Admon R, Sommer T, Stark R, Suzuki H, Van Amelsvoort T, Van Hell E, Vink M, Votinov M, Wotruba D, Bhattacharyya S, Mtac, 2018 The Neural Substrate of Reward Anticipation in Health: A MetaAnalysis of fMRI Findings in the Monetary Incentive Delay Task. Neuropsychology Review 28, 496-506. [PubMed: 30255220]

Wu M, Kujawa A, Lu LH, Fitzgerald DA, Klumpp H, Fitzgerald KD, Monk CS, Phan KL, 2016 Agerelated changes in amygdala-frontal connectivity during emotional face processing from childhood into young adulthood. Human brain mapping.

Yang TT, Menon V, Eliez S, Blasey C, White CD, Reid AJ, Gotlib IH, Reiss AL, 2002 Amygdalar activation associated with positive and negative facial expressions. NeuroReport 13(, 1737-1741. [PubMed: 12395114]

Yeo BTT, Krienen FM, Sepulcre J, Sabuncu MR, Lashkari D, Hollinshead M, Roffman JL, Smoller JW, Zollei L, Polimeni D, Fischl B, Liu H, Buckner RL, 2011 The organization of the human cerebral cortex estimated by intrinsic functional connectivity. Journal of Neurophysiology 106, 1125-1165. [PubMed: 21653723]

Yi JY, Dichter GS, Reese ED, Bell RP, Bartuska AD, Stein JR, Daughters SB, 2019 Neural reward response to substance-free activity images in opiate use disorder patients with depressive symptoms. Drug and Alcohol Dependence 198, 180-189. [PubMed: 30947052]

Drug Alcohol Depend. Author manuscript; available in PMC 2021 January 01. 


\section{Highlights}

- $\quad$ The revised monetary incentive delay task engages key areas of the reward network

- Placebo-controlled d-amphetamine administration elicits a euphoric/liking response

- $\quad$ Reward (amygdala, insula, caudate) regions predicted of amphetamine euphoria/liking 


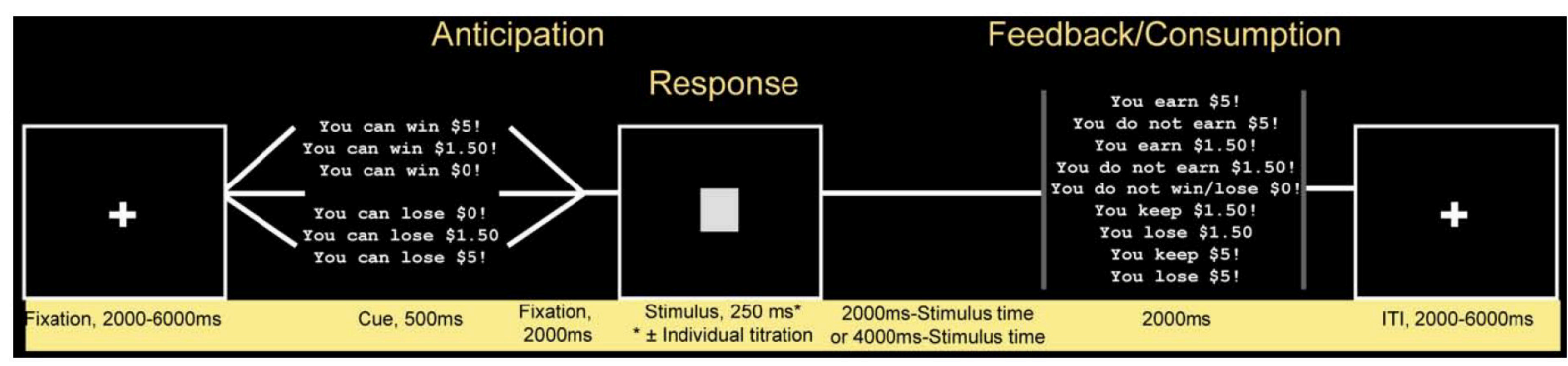

Figure 1.

Illustration of the modified MID task. The cue is one of three cues for either win or loss anticipation, $\$ 0, \$ 1$, or $\$ 5$. The hemodynamic response function (HRF) for anticipation is modeled from between the cue and the stimulus. Consumption is the period after feedback, but is outside the purview of this report. 

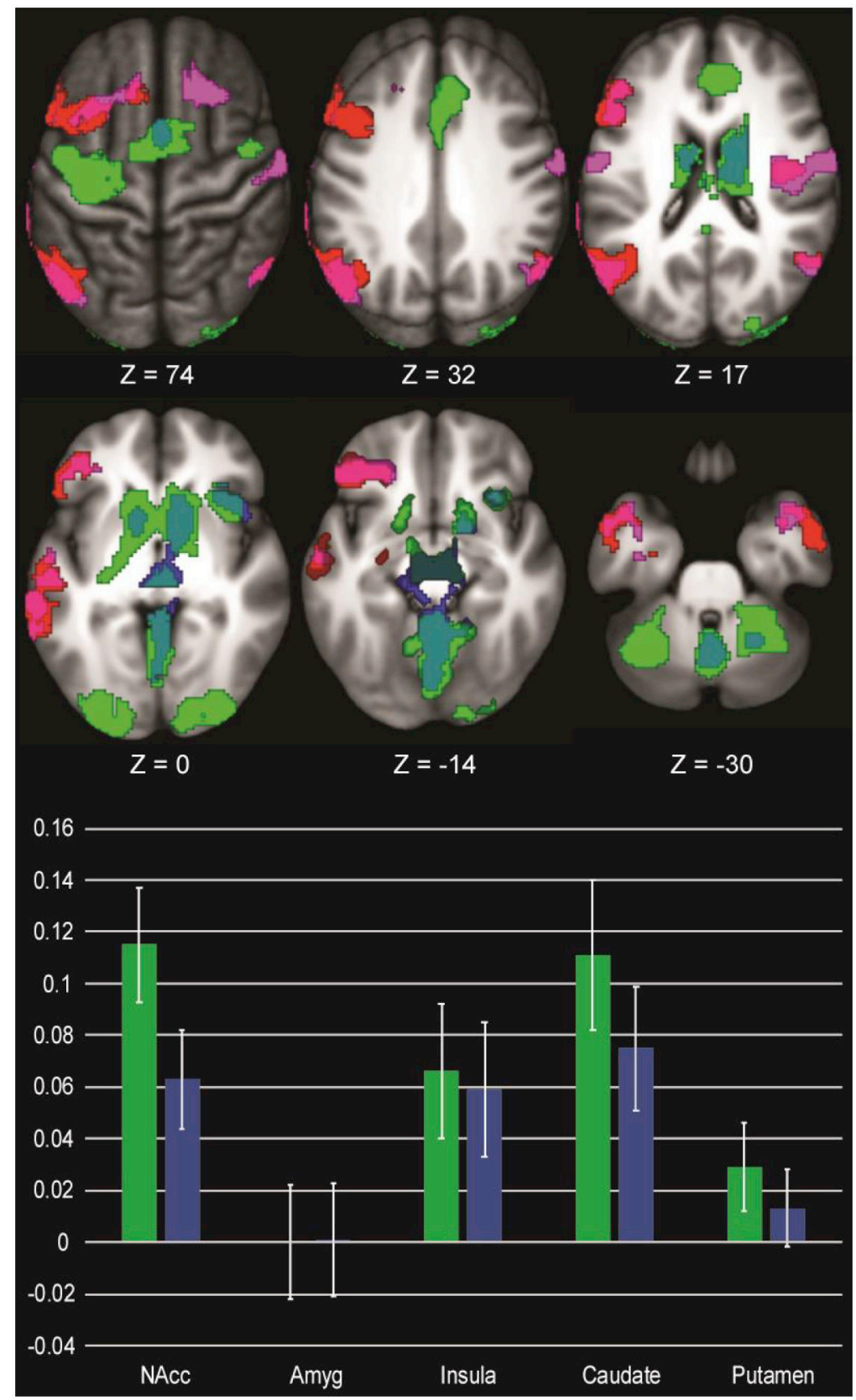

Figure 2.

Panel A demonstrates significant areas of positive activation for anticipation of WinMoney minus WinZero (green) and LossMoney minus LossZero (blue). There are also significant areas of decreased activation for WinMoney minus WinZero (red) and LossMoney minus LossZero (fuscia). Threshold displayed at $\mathrm{p}<.0001$ and $\mathrm{k}>150$. Panel B illustrates activation in extracted ROIs for the WinMoney-WinZero (green) and LoseMoney-LoseZero contrasts (blue). Win has more activation than Loss for NAcc. 

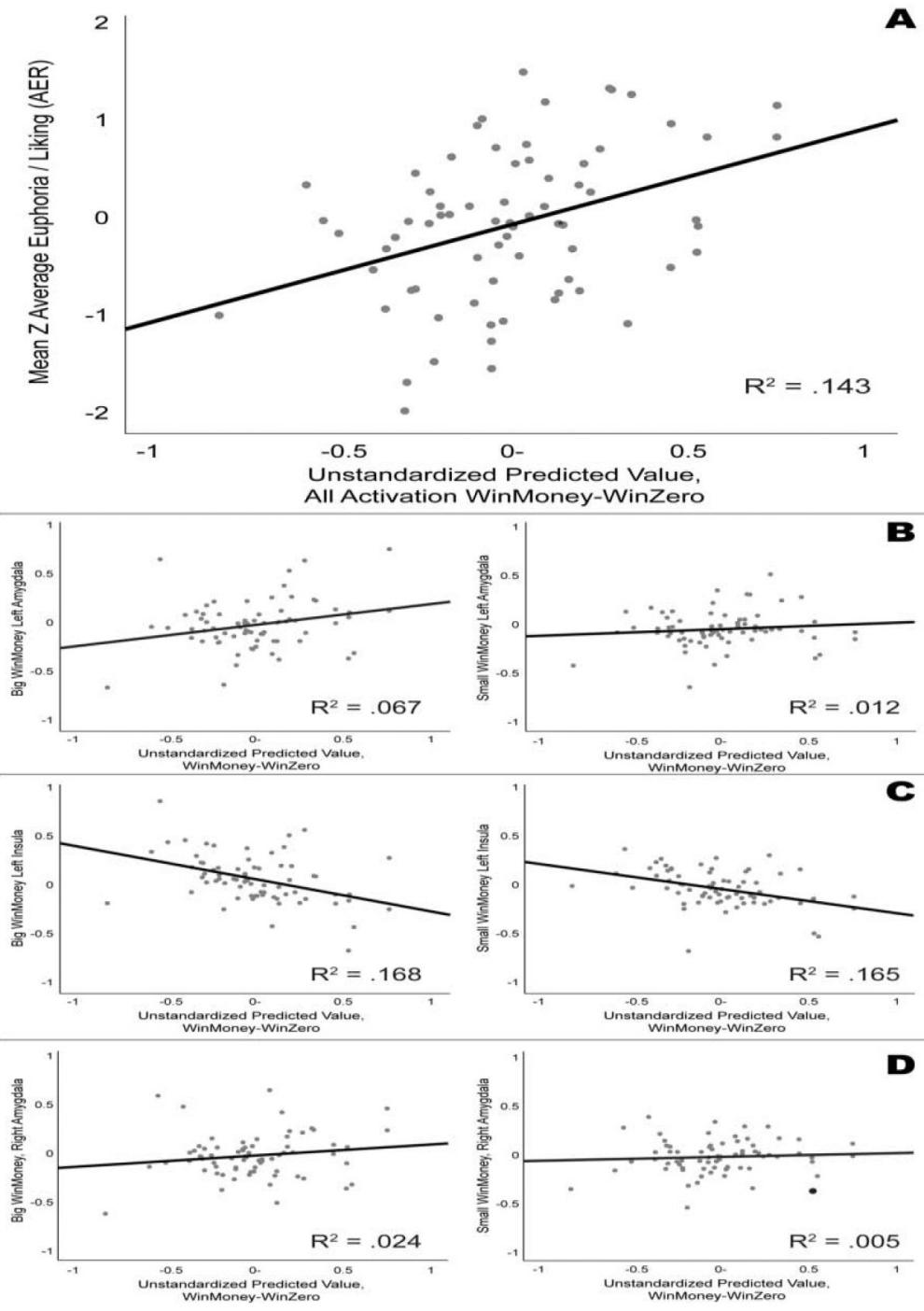

Figure 3.

Scatterplots of Activation in Key Regions of Interest that are predictive of AER. Panel A, unstandardized beta weights from regression model, with top three ROIs, in prediction of euphoria and liking to amphetamine. Panels B through D illustrate that Big wins (\$5) have a larger role in prediction in the model for right and left amygdala, while left insula is relatively similar for Big and Small (\$1) wins. 


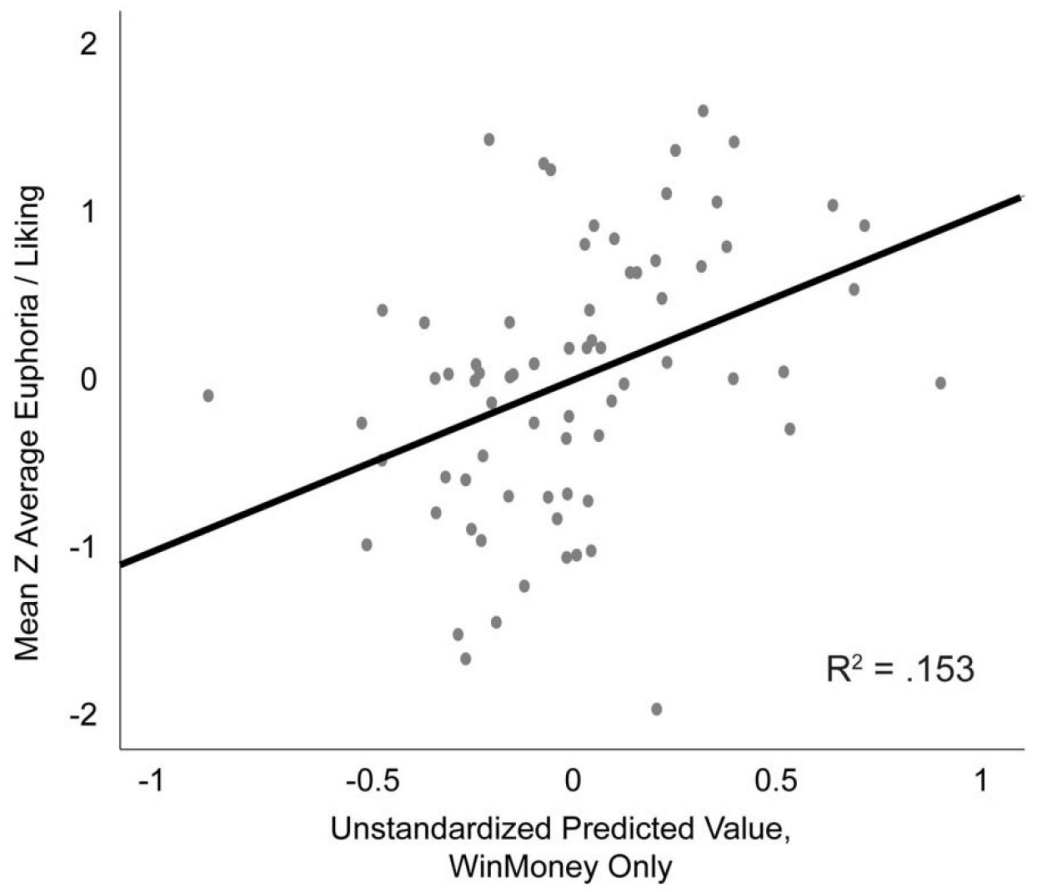

Figure 4.

Scatterplot of Activation in Key Regions of Interest that are associated with AER (without covariates). 
Table 1.

Demographic and Descriptive Variables.

\begin{tabular}{|l|l|}
\hline Demographic & M (SD) \\
\hline Age (years) & $24.5(2.64)$ \\
\hline Sex & $37 \mathrm{M}, 33 \mathrm{~F}, 3$ not stated \\
\hline Education, Years & $15.5(1.51)$ \\
\hline Body Mass Index & $22.7(1.94)$ \\
\hline Tobacco cigarettes per day, out of 21 who reported any use & $0.99(1.86)$ \\
\hline Caffeine drinks per day (N=73) & $1.52(1.0)$ \\
\hline Cannabis joints per month, out of 24 who reported any use & $6.56(7.51)$ \\
\hline Alcohol drinks per week (N=73) & $2.71(1.67)$ \\
\hline
\end{tabular}


Table 2.

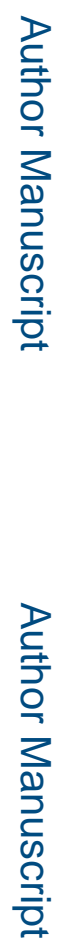

Monetary Incentive Delay as Predictor of AER

\begin{tabular}{|c|l|l|l|}
\hline Monetary Incentive Delay Task predictor & $\mathbf{d f}$ & $\mathbf{F} / \mathbf{t}, \mathbf{p}$ & $\mathbf{R}^{2}, \boldsymbol{B}$ \\
\hline \multicolumn{2}{|l|}{ WinMoney minus WinZero Model } & & \\
\hline Anticipation * & 6,60 & $5.68, .001$ & .22 \\
\hline Left Amygdala & & & .71 \\
\hline Right Amygdala & & & -.27 \\
\hline Left Insula & & & -.54 \\
\hline WinMoney Only Model & & & \\
\hline Anticipation \# & 3,66 & $5.56, .002$ & .17 \\
\hline Left Insula & & & -.42 \\
\hline Right Accumbens & & & -.44 \\
\hline Right Caudate & & & .50 \\
\hline
\end{tabular}

롤

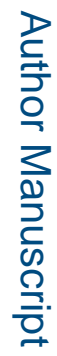

Drug Alcohol Depend. Author manuscript; available in PMC 2021 January 01. 